Ethos (Jurnal Penelitian dan Pengabdian Masyarakat): 159-166

\title{
Pemberdayan Kelompok Ibu-Ibu Rumah Tangga Melalui PemanfaAtan SAMPAH ANORganik MenJadi Kerajinan Tangan
}

\author{
THE HOUSEWIFE'S GROUP EMPOWERMENT THROUGH UTILIZATION OF INORGANIC WASTE \\ INTO HANDYCRAFTS \\ ${ }^{1}$ Chairani, ${ }^{2}$ Sulyono \\ ${ }^{1,2}$ Fakultas ILKOM, IBI Darmajaya, Jl. Zainal Abidin Pagar Alam No. 93, Bandar Lampung \\ e-mail: ${ }^{1}$ chairani@darmajaya.ac.id, ${ }^{2}$ Sulyono79@gmail.com
}

\begin{abstract}
The impact of inorganic waste such as aquabottles, cans, cardboard box, and etc. gives the bad impact for the environment and nature. Utilization of inorganic waste to be used as a handicraft work which have a value. Through the empowerment the group of housewifes in the cluster III Taman Saji, Hajimena Natar village, Lampung Selatan, the utilization of inorganic waste can be one of the solutions for economic changes at the family environment stage.

Keywords: Inorganic waste, handycrafts
\end{abstract}

\begin{abstract}
Abstrak. Dampak keberadaan sampah anorganik seperti botol aqua, kaleng, kardus, dan lain sebagainya memberikan dampak tidak baik bagi lingkungan dan alam. Pemanfaatan sampah anorganik dengan dijadikan hasil karya kerajinan tangan yang dapat memiliki nilai jual. Melalui pemberdayaan kelompok ibu-ibu rumah tangga di dusun III Taman Saji, desa Hajimena Natar, Lampung Selatan, pemanfaatan sampah anorganik ini dapat menjadi salah satu solusi bagi perubahan perekonomian pada tahap lingkungan keluarga.
\end{abstract}

Kata kunci: Sampah anorganik, kerajinan tangan

\section{Pendahuluan}

Keberadaan sampah dilingkungan sekitar khususnya lingkungan dusun III Taman Sari, desa Hajimena, Lampung Selatan dapat dimanfaatkan dan dikelola menjadi bahanbahan produk kerajinan tangan yang layak pakai dan layak jual. Hal tersebut selain dapat mengurangi pembuangan sampah-sampah anorganik yang sulit dihancurkan oleh bakteri dalam tanah, juga dapat memberikan kreativitas bagi kelompok ibu-ibu rumah tangga dalam berkarya dan menghasilkan pendapatan melalui pengisian waktu luang didalam rumah.

\section{Metode Pelaksanaan}

\subsection{Penyebaran tempat sampah dibeberapa titik utama}

Untuk memecahkan permasalahan yang dihadapi oleh sebagian besar ibu-ibu rumah tangga di Desa Hajimena, langkah pertama yang akan tim lakukan adalah dengan memberikan pendampingan berupa pengarahan cara pengumpulan sampah 
plastik dan sampah anorganik lainnya. Pada metode ini kami akan menyediakan tempat sampah yang terdiri dari tempat sampah anorganik (plastik, kertas, kardus, kotak, kaleng, dan lain-lain). Disini tim pelaksana akan bekerja sama dengan ketua RT dan RW setempat untuk berkoordinasi dan bersosialisasi mengenai tempat pembuangan sampah yang dilakukan secara terpisah sesuai jenis sampah. Tempat sampah akan disebar ke titik-titik tertentu (pusat perbelanjaan dalam bentuk warung-warung) sebanyak 20 buah. Hal ini dilakukan sebagai motivasi awal untuk menumbuhkan kesadaran akan kebersihan dan pembuangan sampah pada tempatnya.

\subsection{Sosialisasi dan pelatihan}

Tahapan berikutnya sebelum melakukan pelatihan secara langsung pembuatan kerajinan tangan dari pemanfaatan sampah anorganik, dilakukan sosialisasi terlebih dahulu tujuan dari pelaksanaan pengabdian kepada kelompok ibu-ibu rumah tangga di dusun III Taman Sari, desa Taman Sari, Hajimena, Lampung Selatan.

\subsection{Penyotiran dan pembersihan sampah anorganik}

Pemilihan sampah anorganik yang layak sangat diperlukan untuk menghasilkan produk yang baik. Setelah disortir berdasarkan kelayakan, lalu bersihkan menggunakan air, jika diperlukan dapat menggunakan detergen. Kemudian dikeringkan. Langkah berikutnya yaitu sampah yang sudah dibersihkan akan disortir dan dikelompokkan berdasarkan warna dan besar kecilnya botol-botol tersebut.
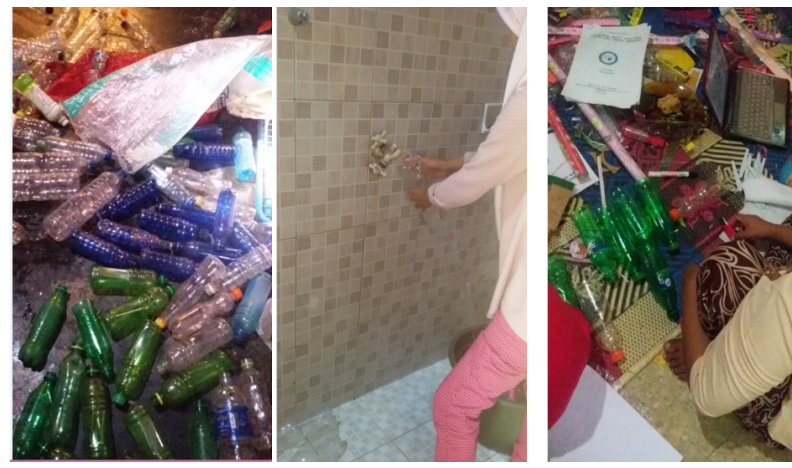

Gambar 1. Pernyortiran dan pembersihan sampah

\subsection{Pembuatan Sapu}

Pembuatan sapu menggunakan botol aqua besar ukuran 1,5 liter berwarna hijau agar tampilan sapu lebih menarik. Sapu ini digunakan untuk menyapu diarea luar rumah atau taman dan tanah 

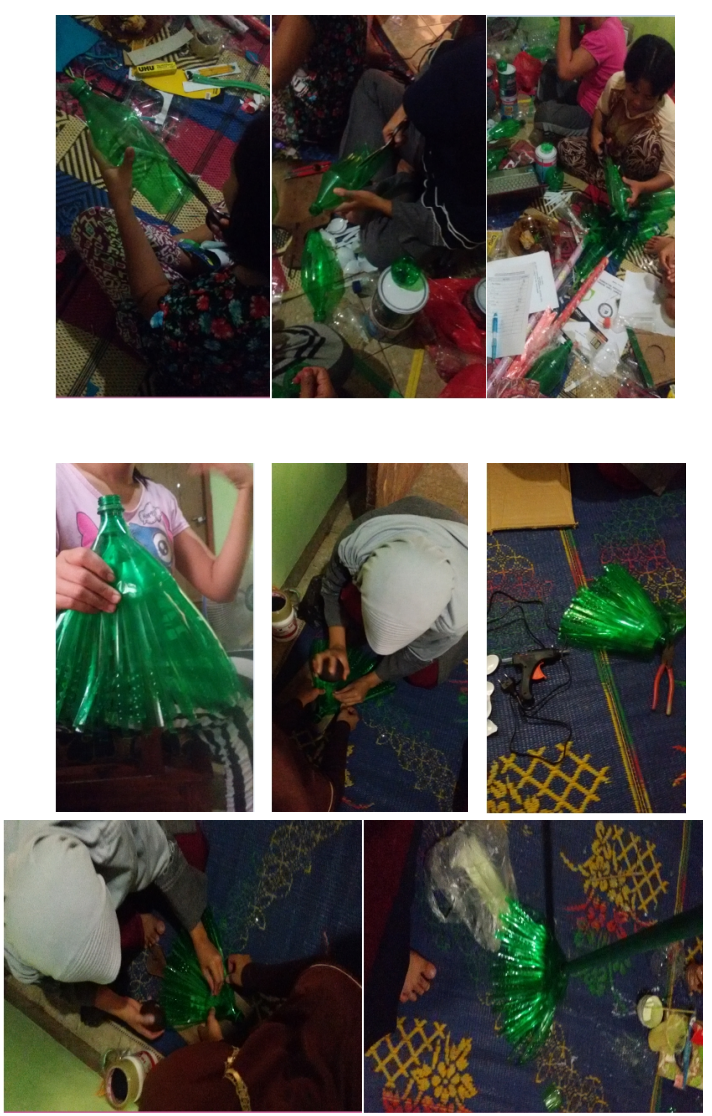

\section{Gambar 2. Cara pengolahan sampah menjadi sapu taman}

\subsection{Pembuatan Kotak Pensil}

Pembuatan kota pensil serta wadah pensil dari botol aqua. Untuk warna dibebaskan karena botol aqua tersebut akan dilapisi oleh kain warna-warni dan juga pernak-pernak penghias lainnya

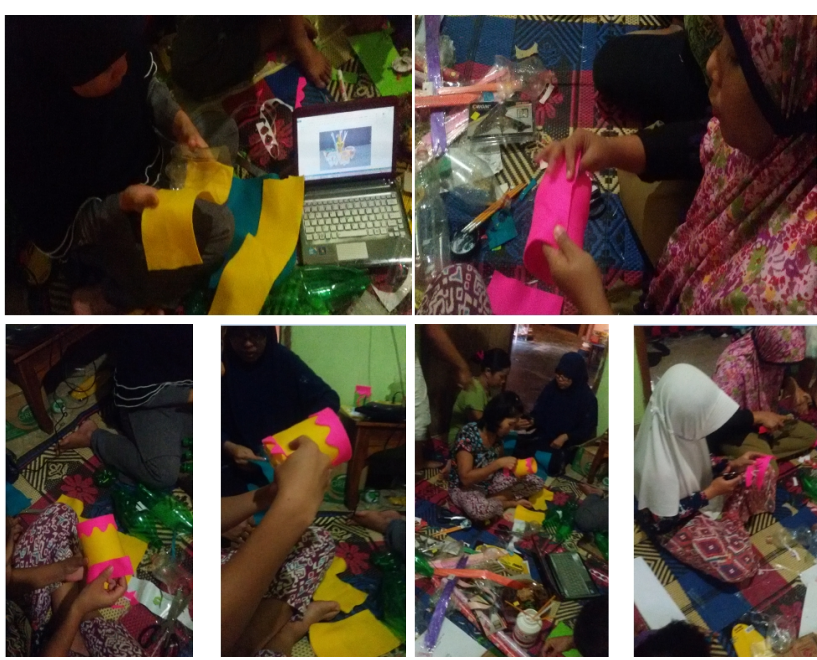



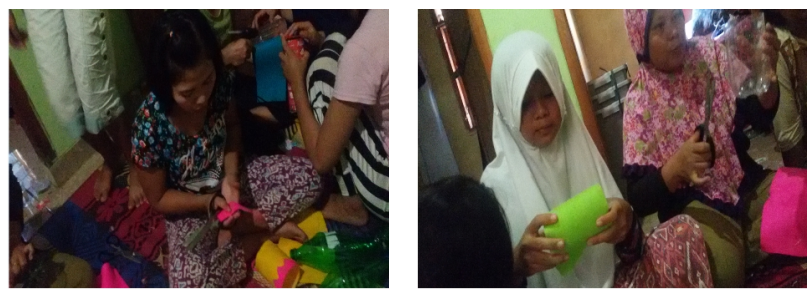

Gambar 3. Pengolahan sampah anorganik menjadi wadah pensil

\subsection{Pembuatan Tirai}

Pembuatan tirai sederhana ini menggunakan dudukan botol aqua bagian bawah dengan pemilihan warna yang seragam, serta ukuran botol aqua yang kecil dan memiliki pola yang sama.
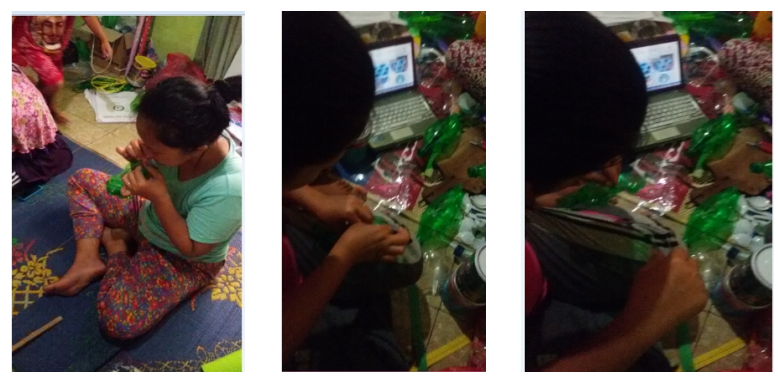

Gambar 4. Pembuatan tirai sederhana

\subsection{Pembuatan Lampu Hias}

Pembuatan lampu hias menggunakan botol gallon ukuran kecil dengan menggunakan penghias dari sendok plastic putih, yang kemudian didalamnya akan diberikan lampu berwarna-warni
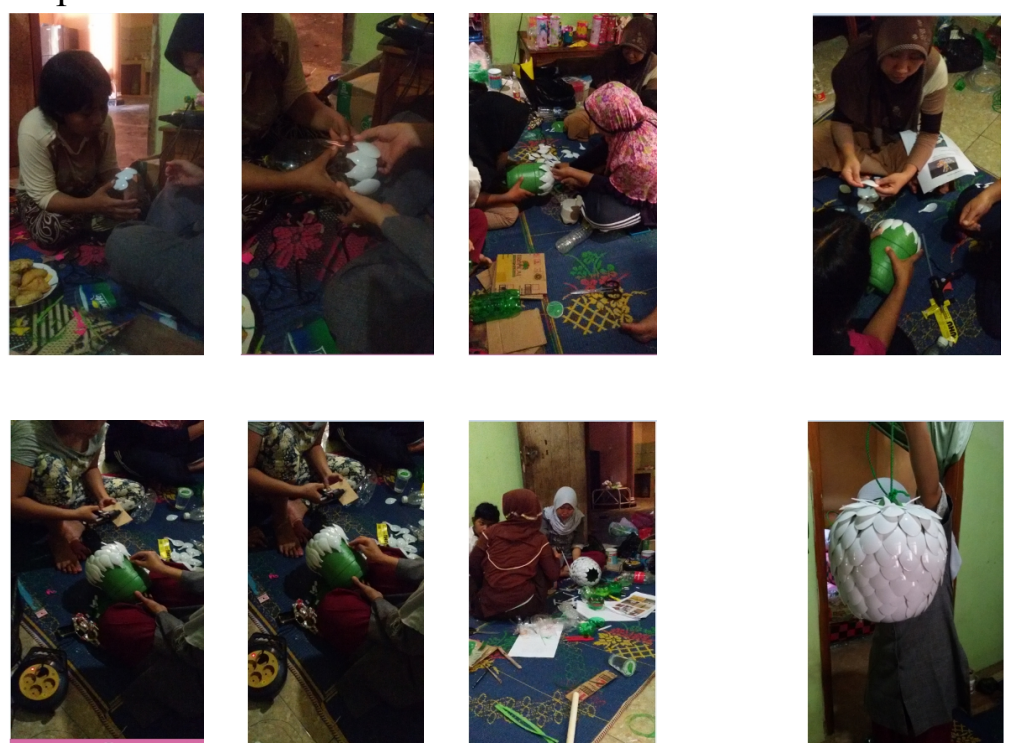

Gambar 5. Pembuatan lampu hias 


\subsection{Pembuatan Pot Bunga Hias}

Pembuatan pot bunga hias dengan model gambar kucing menggunakan botol plastik bekas.
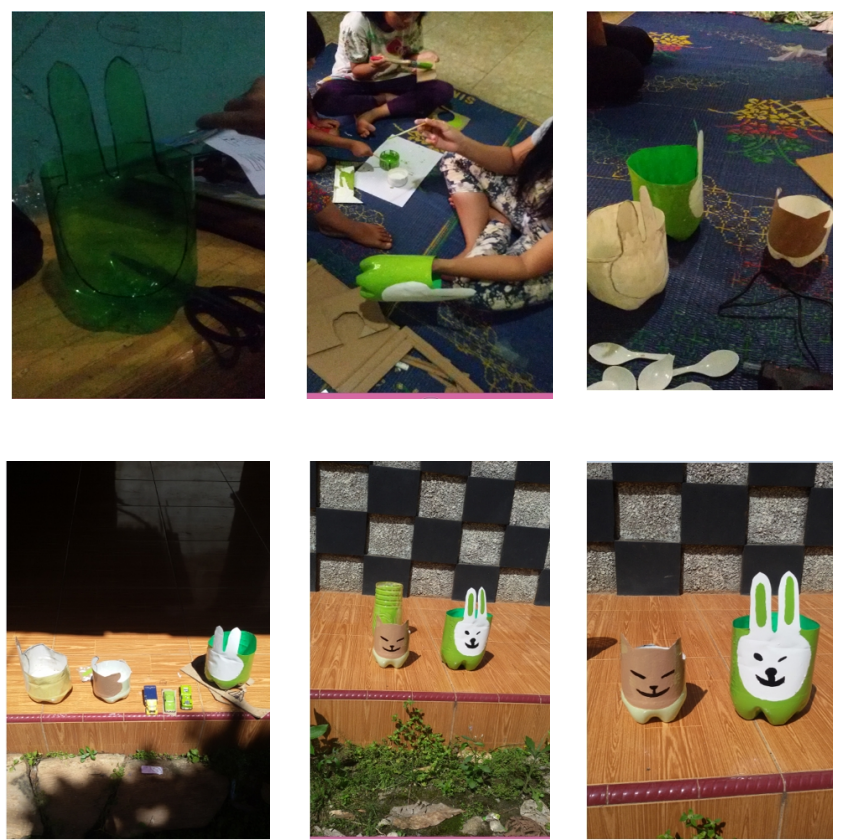

Gambar 6. Pengolahan sampah anorganik menjadi pot bunga hias

\subsection{Pembuatan Dompet Hias Kecil}

Dengan menggabungkan dua buah dudukan botol plastic menggunakan resleting yang direkatkan dengan benang senar ukuran sedang, menghasilkan dompet hias kecil yang berguna untuk menaruh uang logam ataupun peniti dan benda-benda kecil lainnya.
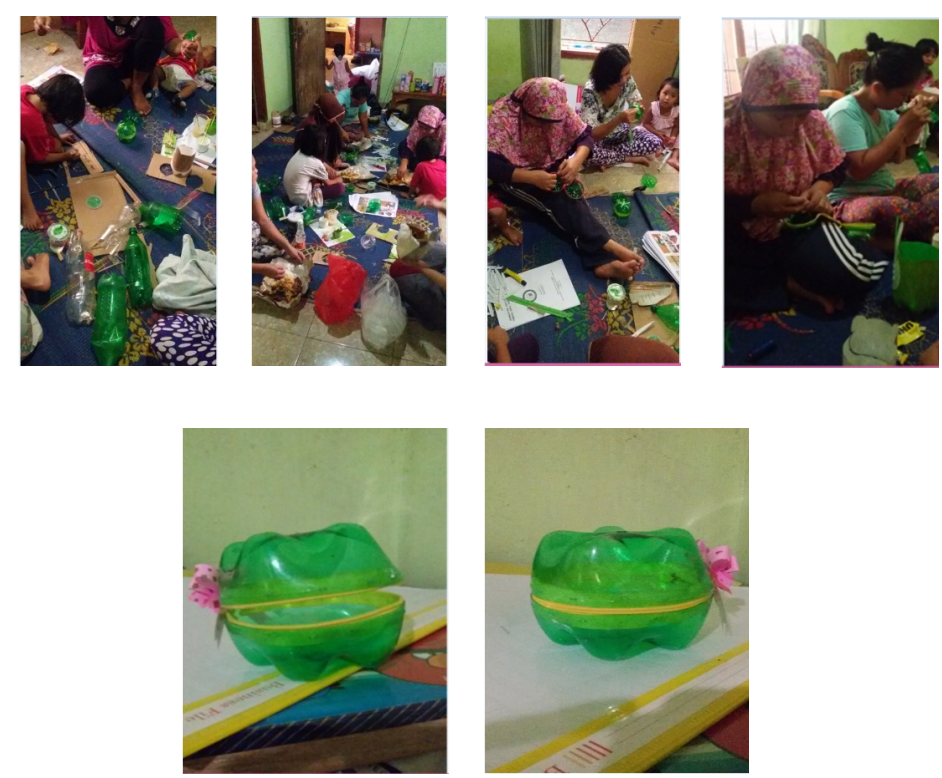

Gambar 7. Pengolahan limbah plastic menjadi dompet kecil 


\subsection{Pembuatan Paper Bag dari Karton}

Dengan mengolah limbah kardus bekas yang dibentuk pola ukuran tas, serta dilapisi kertas kado dan dijahit menggunakan tali raffia menghasilkan paper bag yang menarik
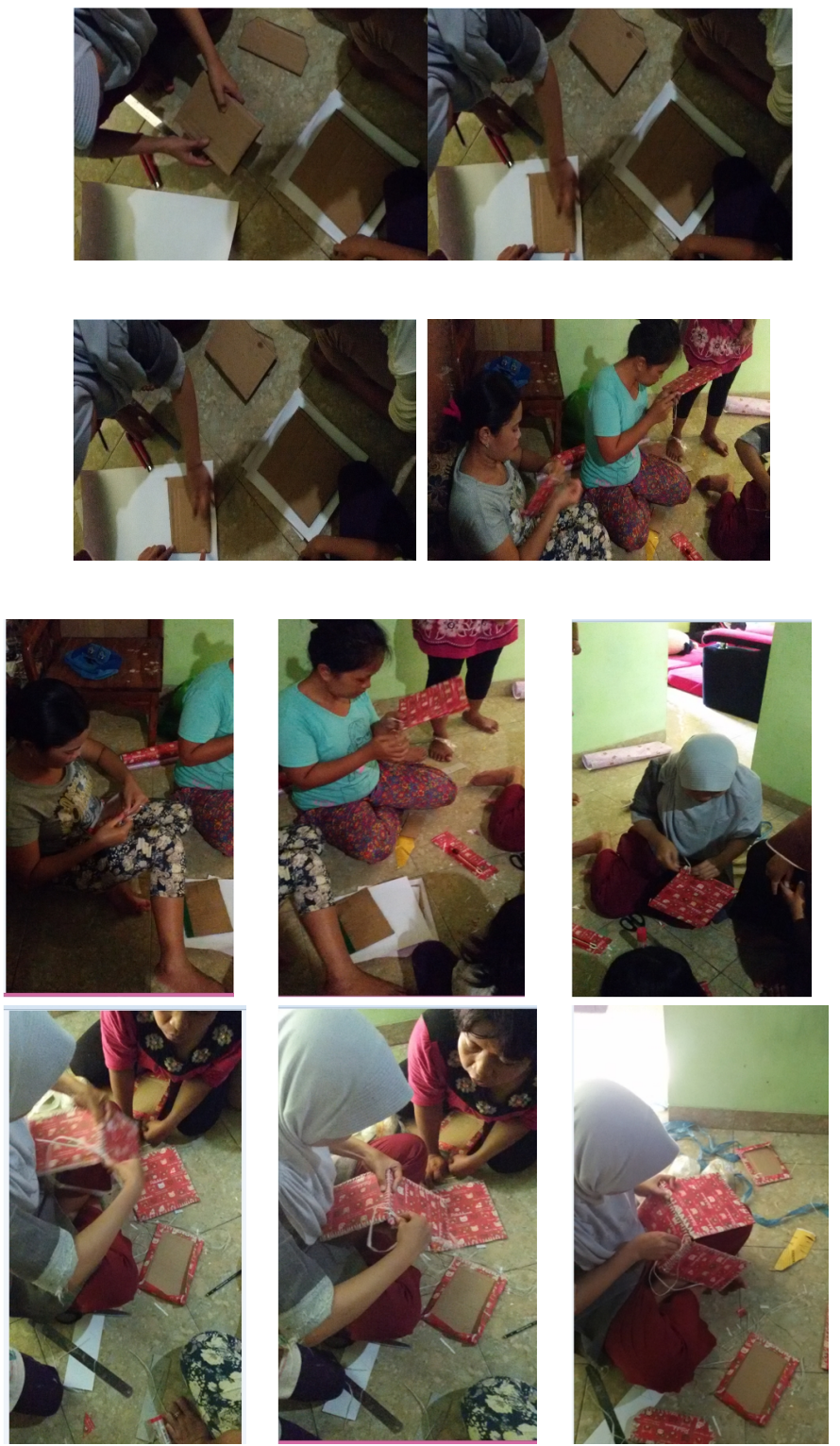

\section{Gambar 8. Pembuatan paper bag dari olahan limbah kardus bekas}

\section{Hasil}

Salah satu hasil dari program pengabdian ini adalah kelompok ibu-ibu rumah tangga pada dusun III Taman Sari memiliki kemampuan dan keterampilan untuk membuat produk-produk kerajinan tangan yang berasal dari sampah plastic, kardus, dan anorganik lainnya.

Produk yang telah diberikan pelatihan cara pembuatannya adalah celengan hias dari dus, lampu hias dari gallon kecil dan sendok plastic, tempat pensil dari botol aqua, 
dompet kecil tempat koin atau tempat menaruh jarum pentol, peniti, dan lain-lain dari botol aqua, sapu taman dari botol aqua (gaganggnya menggunakan gagang sapu bekas yang tidak terpakai), tempat tisu dari botol aqua bekas, pohon cemara hias, tirai dari pantat botol aqua, pot bunga hias dari botol aqua bekas, serta paper bag dari kardus bekas.
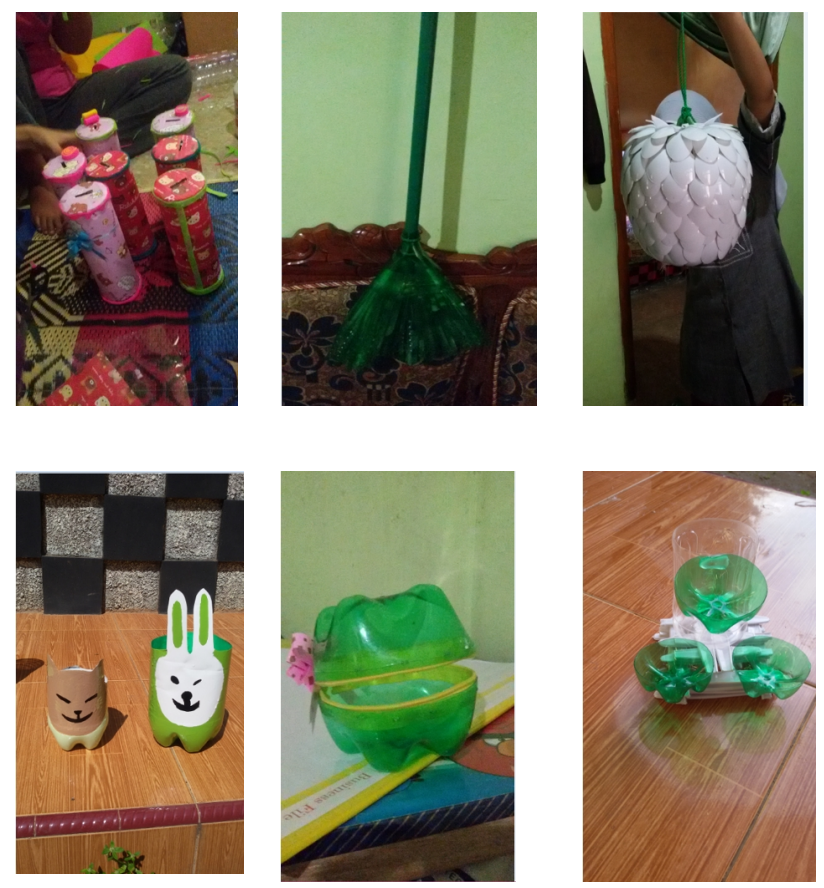

\section{Gambar 9. Hasil kerajinan tangan}

\section{Rencana Berikutnya}

1. Melakukan pembuatan ulang produk dengan kemasan yang layak jual dan mendistribusikannya ke sekitar wilayah Hajimena, Natar, Rajabasa, dan Tanjung Karang melalui pemasaran dengan cara menitipkan produk-produk tersebut ke toko-toko salah satunya mitra 2 yang berada di Raja basa.

2. Membuat blog dan memberikan pelatihan penggunaan blok kepada kepada Ibuibu rumah tangga agar dapat mengelola blog tempat promosi dan pemasaran berbasis teknologi internet (terutama para kader di masing-masing kelompok)

3. Agar kelompok Ibu-ibu rumah tangga memiliki pemasukan tambahan untuk membantu perekonomian keluarga akan diarahkan untuk menyewa tenan secara 1 bulan setelah tahapan pada point (1) selesai. 
166 Chairani, et al.

\section{Kesimpulan dan Saran}

Pemanfaatan sampah anorganik dapat menghasilkan produk-produk kerajinan tangan yang layak pakai dan layak jual. Selain dapat sedikit menganggulangi permasalahan sampah disekitar lingkungan kita, hal tersebut juga dapat menambah kreativitas untuk dapat menghasilkan karya yang dapat dijual dan digunakan oleh masyarakat sekitar.

\section{Daftar pustaka}

Rais Yusuf, 2010, Buku Daftar Isian Dan Profil Desa/Kelurahan, Desa Hajimena, Kecamatan Natar, Lampung Selatan

(http://www.kawankumagz.com/read/9-bahaya-sampah-plastik) 